\title{
A Química dos Cosméticos Numa Perspectiva de Ensino por Projetos
}

J osé Costa de Oliveira Júnior* (Graduando em Química na Universidade Federal de Campina Grande UFCG);

J osé Carlos Oliveira Santos (Professor da UABQ/CES na Universidade Federal de Campina Grande UFCG)

E-mail: junioroliveira.cuite@gmail.com

Resumo: O presente artigo aborda a importância do ensino por projetos no processo de ensino/aprendizagem dos alunos, especificamente para o ensino de química. Ao trabalhar com cosméticos cria-se uma perspectiva real para que o professor dialogue com os alunos e abra mais espaço no seu planejamento para que o aluno construa a sua autonomia, sendo, de fato, um sujeito ativo da sua aprendizagem. Este trabalho aborda o tema cosméticos como organizador dos conteúdos de química enfatizando os aspectos sociais, econômicos e conceituais necessários para o entendimento do tema relacionando-o com o cotidiano, principalmente no que se diz respeito a saúde e higiene pessoal. No desenvolvimento deste projeto relacionou-se o tema cosmético aos conceitos da química lecionados no ensino médio, mais especificamente a Química Orgânica da Escola Orlando Venâncio dos Santos da cidade de Cuité-PB, e teve como mediadores a equipe do subprojeto PIBID/Química. Essas atividades tiveram o objetivo de levar os alunos a um modelo de aprendizagem diferenciada, utilizando-se de métodos que proporcionaram a participação, interação e construção de significados, saberes e competências para sua formação como cidadãos, e também de mostrar que os projetos de ensino são capazes de promover uma aprendizagem mais significativa aos alunos.

Palavras-chave: Ensino por projetos; ensino de química; química orgânica; cosméticos.

Espaço reservado para organização do congresso. 


\section{I ntrodução}

Os projetos de ensino de um modo geral promovem a oportunidade de por em prática e analisar o desempenho dos docentes frente a sua forma de promover a progressão conceitual do tema trabalhado para a aprendizagem de seus alunos, a busca de conhecimentos integradores no ensino das ciências naturais, as relevâncias e carências que certamente surgem quando o professor se põe a trabalhar numa perspectiva de construção de conhecimento, a partir da organização de conteúdos por projetos de ensino.

Segundo Gonçalves et al. (2005) os projetos de ensino e de pesquisa em salas de aula facilitam o processo ensino-aprendizagem, onde promove uma interação entre professor e aluno, formando cidadãos mais críticos, com perfil de pesquisador e enriquece as habilidades profissionais. Além disso, vale salientar que as aulas se tornam mais dinâmicas atraentes, pois os alunos não percebem o tempo passar e ainda aprimoram o conhecimento adquirido. De fato, os projetos de ensino promovem uma inovação nas metodologias de ensino, visto que grandes partes dos professores lecionam de forma tradicionalista e de certa forma tornam suas aulas monótonas e desinteressantes, causando assim uma dificuldade na compreensão dos conteúdos por parte dos alunos.

A necessidade de contextualização, para proporcionar uma compreensão maior dos conceitos químicos, bem como o desenvolvimento de habilidades e competências, para que o aluno possa tomar decisões conscientes, constituem os elementos fundamentais das novas Diretrizes Curriculares Nacionais (BRASIL, 1999). De acordo com Nunes e Adorni (2010), na sociedade atual evidencia-se uma alta dose de informações, que nem sempre são devidamente tratadas. A escola tem se tornado responsável por atender a essa demanda dos educandos. Nesse sentido, grande parte desta tarefa cabe ao profissional professor que, no desenvolvimento do conhecimento técnico científico, tem de desenvolver cada vez mais habilidades em seus alunos, o que requer, em muitos casos, um trabalho amplo e contextualizado.

Adotamos projetos de ensino como [...] propostas pedagógicas disciplinares ou interdisciplinares, compostas de atividades a serem executadas pelos alunos, sob a orientação do professor, destinadas a criar situações de aprendizagem mais dinâmicas e efetivas, atreladas às preocupações da vida dos alunos pelo questionamento e pela reflexão, na perspectiva de construção de conhecimento e da formação para a cidadania e para o trabalho. (PAULINO FILHO et al., 2004, p. 266).

Em sua concepção, a pedagogia de projetos sugere romper com as formas tradicionais de organização curricular, oferecendo uma alternativa à maneira rígida e quase intransponível de como as disciplinas e os conteúdos estão presentes nos livros didáticos e no planejamento dos professores. Ao trabalhar com temas, os projetos abrem uma perspectiva real para que o professor dialogue com os alunos e abra mais espaço no seu planejamento para que o aluno construa a sua autonomia, sendo, de fato, um sujeito ativo da sua aprendizagem.

Um programa que muito ajuda a trabalhar os projetos de ensino é o Programa Institucional de Bolsas de Iniciação à Docência (PIBID), que promove a inserção de graduandos como bolsistas nas escolas públicas proporcionando-lhes experiência e qualificação como futuros docentes através da convivência no cotidiano da comunidade escolar. Dentro dessa perspectiva realizou-se, na Escola Estadual de Ensino Médio e Inovador Orlando Venâncio dos Santos, situada em Cuité-PB, com uma turma de $3^{\circ}$ ano um projeto intitulado A química dos cosméticos, o qual se destinou a problematizar o tema de forma contextualizada e interdisciplinar, apresentando aspectos como definição e classificação de cosméticos, riscos, aspectos históricos, químicos e biológicos, com o intuito de que os alunos se posicionassem de forma crítica e preventiva frente ao modo como a temática cosméticos é veiculada na sociedade.

O principal objetivo deste trabalho é abordar a importância dos projetos de ensino especificamente na disciplina de química, propondo metodologias que facilitem o processo de ensino/aprendizagem dos alunos. Sendo assim buscou-se outros objetivos específicos, tais como: fugir do ensino tradicional; trabalhar com temas de maneira a problematizá-los; tornar o aluno um sujeito ativo na sua aprendizagem; buscar conhecimentos que podem ser trabalhados através do tema; possibilitar uma participação mais efetiva dos alunos envolvidos; motivar a aprendizagem do ensino; facilitar a construção de conhecimentos; buscar uma maior compreensão dos conteúdos envolvidos e favorecer o uso da interdisciplinaridade ao abordar os conteúdos. E nessa perspectiva desenvolveu-se 
este trabalho visando promover uma inovação na forma de lecionar os conteúdos da disciplina de química, pois a forma tradicionalista de ensinar ainda é muito adotada pelos professores.

\section{Metodologia}

Esta pesquisa enquadra-se na proposta metodológica de ensino por projetos citada por autores como Moura e Barbosa (2006), Pacheco (2007) e Hernandez (1998), os quais defendem o processo de ensino e aprendizagem que ocorre por meio de projetos subdivididos em, ao menos, três componentes estruturais básicos: problematização do tema, desenvolvimento e plano de avaliação. O projeto desenvolveu-se na Escola Estadual Orlando Venâncio dos Santos, localizada na zona urbana do município de Cuité no estado da Paraíba, tendo um período de execução ocorrido entre abril e agosto do corrente ano com carga horária total de trinta horas. O público alvo da pesquisa foram trinta e nove alunos de uma turma do terceiro ano do Ensino Médio regular.

A referida escola adota o Programa de Ensino Médio Inovador, o qual possui os chamados macro campos na proposta do Projeto de Redesenho Curricular. Entre os macrocampos obrigatórios está o de Iniciação Científica e Pesquisa, no qual foram realizadas as aulas ministradas no decorrer deste projeto. A abordagem do projeto direcionou-se à construção de conhecimentos voltados para o âmbito interdisciplinar e contextualizado desenvolvendo a aprendizagem dos conceitos inerentes da química orgânica visando uma melhor compreensão das funções orgânicas oxigenadas comumente utilizadas na fabricação de cosméticos comercializados no nosso cotidiano.

A problematização do tema consistiu em momentos de reflexões, discussões e informações apresentadas de modo contextualizado e interdisciplinar por meio de aulas expositivas e leituras, coletivas e individuais de textos, partindo dos aspectos mais relevantes como os fatores que caracterizam os cosméticos, os riscos apresentados pelo uso indevido, o seu uso e desenvolvimento ao longo da história, os processos químicos e biológicos, etc. Com base nestas informações, os alunos realizaram duas atividades: a produção de painéis em grupos com imagens que remetessem o que foi visto nas aulas supracitadas e a produção de textos individuais com o intuito de trabalhar o uso das linguagens.

O desenvolvimento do projeto consistiu no uso de instrumentos metodológicos como a experimentação e os jogos didáticos na construção dos conhecimentos e objetivos almejados. Os experimentos realizados foram testes de identificação de grupos funcionais que consistem na formação de gases ou na mudança de coloração ocorrida quando é realizada a mistura de um reagente específico para cada função orgânica. Os experimentos foram realizados no laboratório de ciências da referida escola. As funções orgânicas identificadas foram alcoóis, fenóis, aldeídos, cetonas e ácidos carboxílicos. Os jogos didáticos utilizados foram o jogo da memória no qual os alunos se organizaram em grupos e realizaram a pesquisa das estruturas químicas das funções orgânicas para a montagem das peças que relacionam as fórmulas estruturais à nomenclatura ou a função orgânica e o jogo do percurso que consiste num tapete com fases progressivas onde os alunos são as próprias peças e avançam à medida que vão respondendo corretamente as questões lançadas.

O plano de avaliação desta pesquisa se aplica a partir da abordagem qualitativa em que os resultados são expressos por meio de descrições ilustradas pelas falas das pessoas com intuito de dar o fundamento concreto a estas descrições (TRIVIÑOS, 1987 apud MUNCHEN, 2012). Deste modo, a avaliação do projeto ocorreu atendendo a interação e observação participante e ainda pela aplicação de questionários por meio dos quais ocorreu o levantamento da aprendizagem dos alunos resultante da metodologia proposta, bem como das atividades realizadas no decorrer do projeto.

\section{Resultados e Discussão}

Com base no tema "cosméticos”, o caráter investigativo do projeto foi adotado já no início com o levantamento nos conhecimentos prévios dos alunos e a relação do tema com a realidade dos estudantes para, deste modo, planejar e elaborar as atividades apropriadas às necessidades da turma envolvida.Este levantamento ocorreu por meio de um questionário inicial com cinco perguntas abertas que continham uma avaliação sobre a importância deste tema para os alunos de modo que fosse possível utilizá-lo como tema gerador. As questões estão apresentadas no quadro a seguir: 
Quadro 1 - Questionário inicial.

1 - O que você compreende por cosméticos?

2 - De acordo com seu entendimento sobre cosméticos, quais funções estes produtos apresentam?

3 - Classifique de zero a dez a importância que os cosméticos apresentam em sua vida. Justifique.

4 - Com que freqüência você utiliza produtos cosméticos em seu dia-a-dia? Se não usa, explique os motivos.

5 - De acordo com sua observação sobre os cosméticos na vida das pessoas que você convive como você classifica a importância destes produtos para estas pessoas?

Fonte: autor

As respostas dadas pelos alunos foram bem diversificadas e todos demonstraram algum conhecimento do tema pelo motivo de ser tão comum ao seu cotidiano. Na primeira questão, dos trinta e nove alunos, vinte e seis definiram os cosméticos como produtos usados para a obtenção da beleza e melhoramento da aparência. Alguns ainda relacionaram os cosméticos à higiene e saúde da pele, citando a indústria como forma de obtenção destes. As principais respostas dadas pelos alunos podem ver abaixo:

1. São relativos à beleza, produtos constituídos por substancias sintéticas e naturais que vem desde os mais simples aos mais modernos.

2. Produtos tanto para a beleza quanto para higiene como shampoo, condicionador, sabonete, maquiagem, batom.

3. Produtos industriais, para cuidar da beleza, entre diversos ramos como pele e cabelos.

Na segunda questão, trinta e quatro alunos atribuíram aos cosméticos a função de melhorar a vida das pessoas em aspectos como a beleza, a higiene e ao bem estar, ficando clara a percepção dos alunos da aplicação cotidiana dos cosméticos na manutenção da beleza. Tais como:

1. Eles nos auxiliam a embelezar, nos cuidados da pele, na hidratação e na proteção.

2. Uma forma de tentar melhorar a sua autoestima, algo que você não gosta pele, fora aqueles que perfumam a pele.

Com relação à terceira questão, trinta alunos classificaram acima de cinco a importância que os cosméticos apresentam em sua vida, justificando, entre outros, que fazem uso diário e que sem eles a higiene é impossível de ser mantida. Os demais que classificaram abaixo de cinco, explicam que não gostam muito de usar esses produtos ou que só usam o básico e quando vão sair. Tais como:

1. Dez alunos disseram por que precisamos muito deles para a nossa higiene.

2. Nove alunos disseram porque há produtos de higiene pessoal que acho essencial o uso. E as maquiagens gostam de usar, mas não muito.

3. Nenhum aluno justificou como desnecessário.

4. Quatro alunos disseram que só usam quando vou sair.

No quarto questionamento, trinta e dois alunos relataram que utilizam cosméticos diariamente ou constantemente. Um dos alunos que responderam não utilizar os cosméticos justificou-se pelo fato de ser homem, o que nos leva a entender que sua concepção de cosméticos é ainda um tanto reduzida, atribuindo aos produtos de beleza utilizados pelas mulheres como maquiagens, esmaltes, etc. Tais como:

1. Todos os dias. Utilizo protetor, pó, rímel...

2. Todos os dias e bastante. Perfume, creme, etc.

3. Não uso, sou homem.

No quinto e último questionamento os alunos avaliaram a importância dos cosméticos desta vez para as pessoas com as quais convive para que eles próprios fizessem uma análise mais geral do uso destes produtos. Neste, a grande maioria dos alunos reconhecem que muitas pessoas têm um grande interesse no uso dos cosméticos pelos mesmos motivos já apresentados: a manutenção da beleza, a higiene e o bem estar pessoal. 
Este questionário foi essencial, pois com ele pode-se conhecer as opiniões dos alunos a respeito dos cosméticos e a partir disso elaborar um projeto de ensino capaz de contextualizar e dinamizar as aulas sobre o tema "cosmético", através de metodologias inovadoras fugindo do ensino tradicional. Com base nesses resultados, percebe-se que os cosméticos poderiam ser abordados em um projeto de ensino bastante interessante proporcionando muitos debates e uma aprendizagem significativa para os alunos, tendo em vista que sua aplicação e uso estão muito presente em seu cotidiano.

Em se tratando dos resultados obtidos na etapa inicial de problematização do tema, os alunos utilizaram imagens diversificadas para apresentar seus conhecimentos sobre o tema buscando compreender, através das imagens, a maior quantidade de informações possíveis demonstrando um entendimento de grande parte dos assuntos vistos na problematização. Percebeu-se que os alunos motivaram-se nas atividades em conjunto, uma vez que na confecção dos cartazes (Figura 1), como esperado, houve muita interação e interesse dos estudantes, os quais demonstraram criatividade e sincronismo das opiniões de modo que confeccionaram os cartazes e puderam desenvolver e apresentar seus conhecimentos, bem como aprimorar a capacidade de trabalho em grupo, e isso é uma das vantagens de se lecionar através de projeto de ensino onde abre espaço para que os alunos participem de uma forma mais integrada nas atividades.

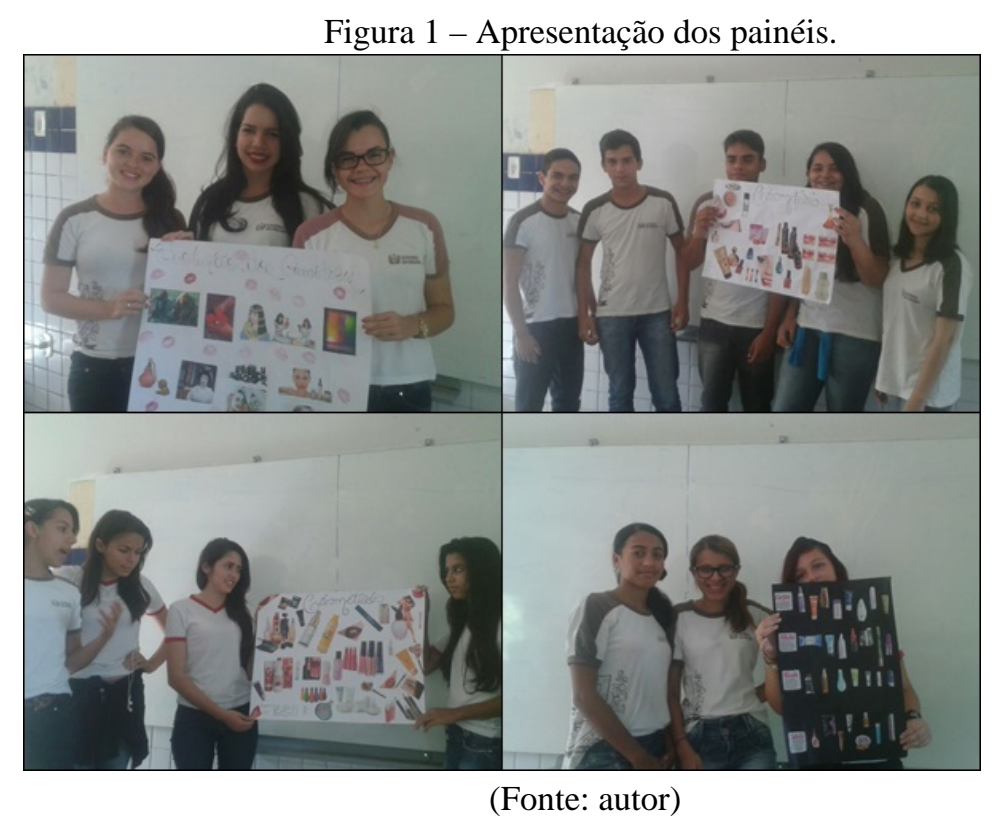

Para Gonçalves e Marques (2006), o trabalho em equipe apresenta uma função socializadora que auxilia no aprimoramento das habilidades sociais, pois os alunos precisam entrar em consentimento sobre assuntos que geram diferentes interpretações, o que pode ser alcançada pelo diálogo e pela comunicação. Deste modo, o trabalho em equipe foi de suma importância na aprendizagem, pois aprimorou-se o diálogo, a autonomia coletiva, a co-responsabilidade e o respeito à opinião do outro.

No que diz respeito aos experimentos utilizados (Figura 2), observou-se uma notável demonstração de interesse por parte dos alunos em visualizar e compreender a presença das funções orgânicas em cosméticos que eles utilizam diariamente e, assim, mostraram-se motivados a aprender, questionar e discutir sobre o que foi estudado. As práticas no laboratório da escola promoveram uma grande motivação e interação com toda a turma, onde todos participaram dos experimentos. A experimentação promoveu uma interação maior em sala de aula e instigou os alunos a aprender novos conhecimentos, pois foi apresentado a eles a relação entre teoria e prática. 
Figura 1 - Experimentos realizados pelos alunos

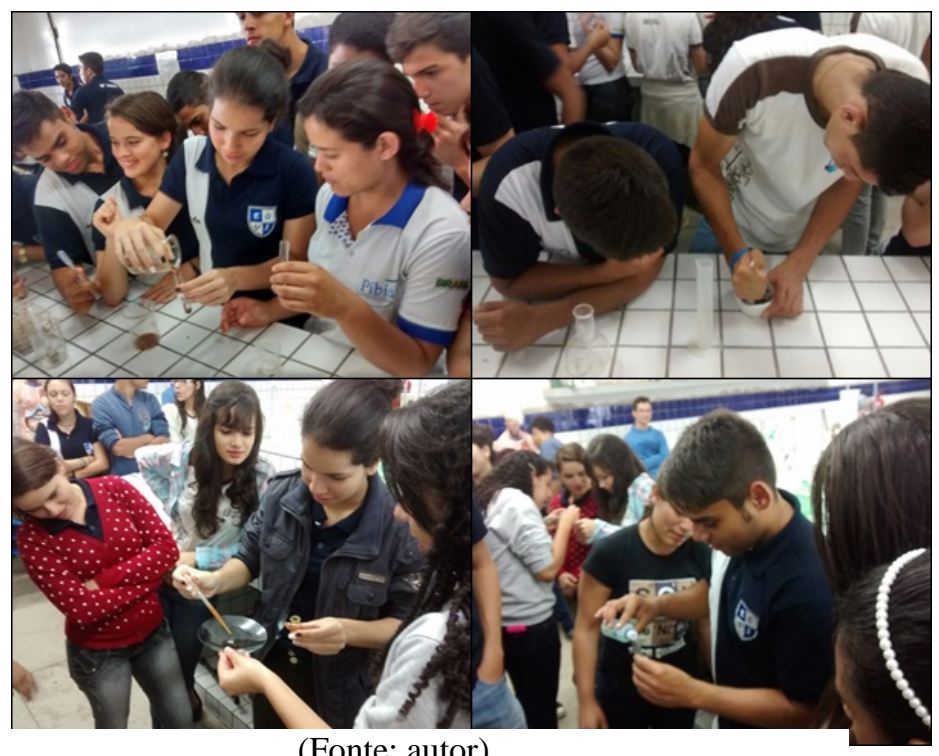

(Fonte: autor)

Sobre a utilização dos jogos nesta pesquisa, destaca-se a importância desta atividade nos projetos de ensino, onde trás o dinamismo para a sala de aula e os alunos aprendem os conteúdos de uma forma divertida. Os jogos (Figura 3) foram muito importantes para saberem-se as dúvidas e dificuldades que os alunos por ventura ainda tinham nesta fase do projeto quanto aos assuntos e conceitos trabalhados e, com base nessas dificuldades e por meio dos jogos, aos poucos desenvolveuse junto aos alunos os conhecimentos ainda não adquiridos.

Figura 3 - Jogos lúdicos realizados pelos alunos

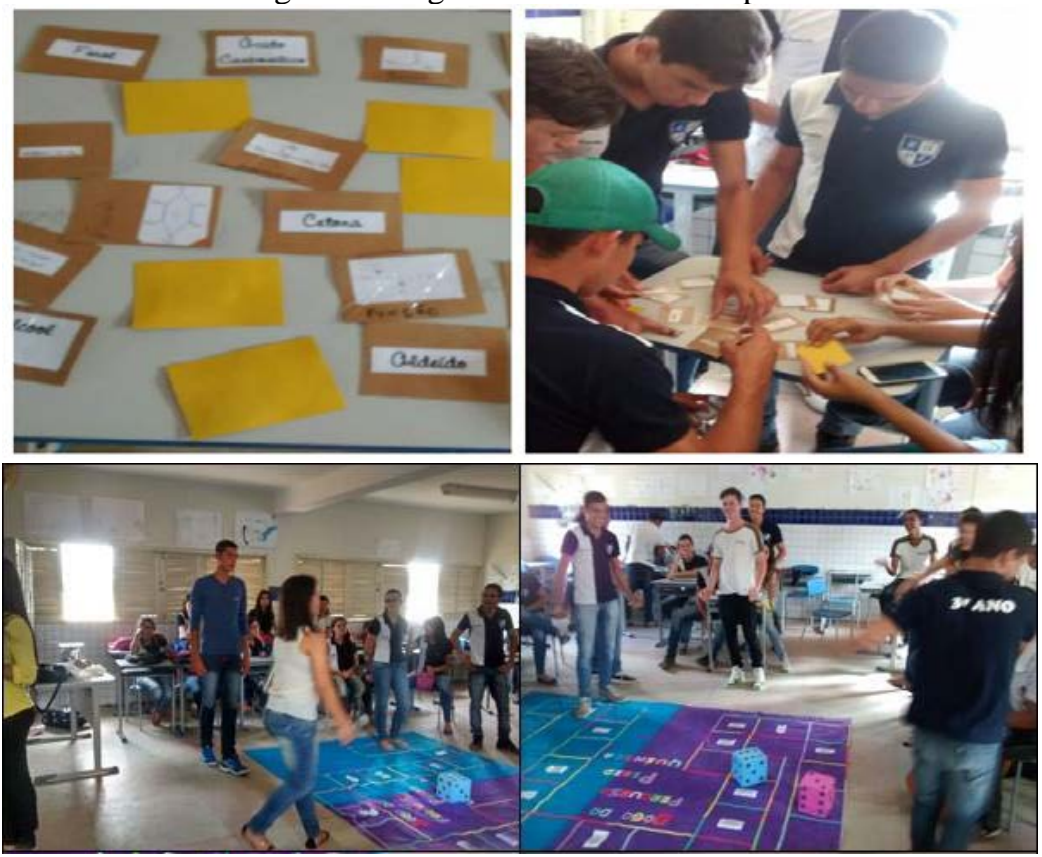

Fonte: autoria própria (2015)

Ao se trabalhar com a pedagogia de projetos, o profissional da educação busca uma contextualização para o ensino com o objetivo de promover uma evolução conceitual no aprendiz a partir de uma experiência vivenciada. Ao participar de um projeto, o aluno está envolvido numa experiência educativa em que o processo de construção de conhecimento está integrado às práticas vividas (GIROTTO, 2003; OLIVEIRA, 2006). 


\section{Conclusão}

O uso da pedagogia de projetos de ensino sobre os cosméticos abordando os conceitos químicos possibilitou uma participação mais efetiva dos alunos em sala de aula. A turma tinha um comportamento muito disperso e grande desinteresse com relação à disciplina química. Os alunos consideraram que o desenvolvimento de projetos de ensino em disciplinas é uma abordagem relevante, pois possibilitou o relacionamento dos mesmos com o objeto de aprendizagem, resolvendo problemas e integrando conceitos que levaram a produção do conhecimento.

A partir do projeto, o comportamento, o interesse e a motivação para a aprendizagem de química mudaram conseqüentemente, havendo assim uma prática de ensino diferenciada, construída coletivamente, resultando numa aprendizagem dos conteúdos trabalhados. O trabalho dessa forma mudou o foco da sala de aula do professor para o aluno, da informação para o conhecimento, da memorização para a aprendizagem pela ação, conforme propõe a pedagogia de projetos. Também equilibrou teoria e prática, dividindo responsabilidades e tarefas e, discutindo os processos de forma contextualizada. Ao trabalhar com projetos, professor e aluno assumiram a condição de pesquisadores e co-responsáveis pelo processo de aprendizagem.

\section{Chemistry of Cosmetics a Perspective for Teaching by Projects}

Albstract: This article discusses the importance of teaching by projects in the teaching / learning process of the students, specifically for chemistry teaching. When working with cosmetics it creates a real prospect for the teacher to dialogue with students and open more space in their planning for the student to build their autonomy, and, in fact, an active subject of their learning. This paper addresses the cosmetic theme as organizer of chemical content emphasizing the social, economic and conceptual aspects required for the issue of understanding relating it to everyday life, especially when it relates to personal health and hygiene. In the development of this project was related to cosmetic theme to the concepts of chemistry taught in high school, specifically the School of Organic Chemistry Orlando Venancio Santos City Cuité-PB, and had as mediators subproject team PIBID / Chemistry. These activities had the goal of bringing students to a different learning model, using methods that have provided the participation, interaction and construction of meanings, knowledge and skills to their training as citizens, and also to show that educational projects They are able to promote more meaningful learning students.

Keywords: Teaching by projects; chemistry education; organic chemistry; cosmetics.

\section{Referências bibliográficas}

BRASIL, Ministério da Educação. Parâmetros Curriculares Nacionais, Brasília, 1999.PAULINO FILHO, J.; NUÑEZ, I.B. e RAMALHO, B.L. Ensino por projetos: uma alternativa para a construção de competência no aluno. Porto Alegre: Sulina, 2004.CUNHA, M. B. jogos no ensino de química: considerações teóricas para sua utilização em sala de aula. Química Nova na Escola, v.34, p. 9298, 2012.

GARCIA, V. M. O desenvolvimento da argumentação e da linguagem científica por graduandos em química mediante a produção textual. In: Anais do XVI Encontro Nacional de Ensino de Química e X Encontro de Educação Química da Bahia. Salvador, BA, Brasil, 2012.

GIROTTO, G. G. S. C. Pedagogia de Projetos: (re) significação do processo ensino/ aprendizagem. Projeto de Pesquisa. Núcleo de Ensino - Faculdade de Filosofia e Ciências UNESP - Campus de Marília - 2002 a 2003. 
GONÇALVES, F. P. Como é ser professor de química: histórias que nos revelam. In:Anais do IV Encontro I bero-Americano de Coletivos Escolares e Redes de Professores que fazem Investigação na sua Escola, 2005. UNIVATES, Lageado - RS.

HERNÁNDEZ, F.; VENTURA, M.A organização do currículo por projetos de trabalho. Tradução de J ussara Haubert Rodrigues. 5. ed. Porto Alegre: Artes Médicas, 1998.

MOURA, D. G.; BARBOSA, E. F. Trabalhando com Projetos - Planejamento e Gestão de Projetos Educacionais. Editora Vozes, Petrópolis-RJ, 2006.

MUNCHEN, S. Cosméticos: uma possibilidade de abordagem para o ensino de Química. Dissertação de Mestrado. Universidade Federal de Santa Maria, 2012.

NUNES, A. S.; ADORNI, D.S. O ensino de química nas escolas da rede pública de ensino fundamental e médio do município de Itapetinga-BA: O olhar dos alunos. In: Anais do Encontro Dialógico Transdisciplinar, Vitória da Conquista, 2010.

OLIVEIRA, C. L. Significado e contribuições da afetividade no contexto da Metodologia de Projetos na Educação Básica. Dissertação de Mestrado. CEFET-MG, Belo Horizonte-MG, 2006.

PACHECO, R.A. Ensinar Aprendendo: A Práxis Pedagógica do Ensino por Projetos no Ensino Fundamental. Revista PerCursos, v. 8, n. 2, p. 19-40, 2007.

SILVA, B.; BEZERRA, V. S.; GREGO, A.; SOUZA, L. H. A.A Pedagogia de Projetos no Ensino de Química - O Caminho das Águas na Região Metropolitana do Recife: dos Mananciais ao Reaproveitamento dos Esgotos. Química Nova Na Escola. 2008.

VEIGA, M. S. M.; QUENENHENN, A.; CARGNIN, C.; O ENSINO DE QUÍ MICA: algumas reflexões. Anais da I JORNADA DE DIDÁTICA - O ENSINO COMO FOCO I FÓRUM DE PROFESSORES DE DI DÁTI CA DO ESTADO DO PARANÁ. CEMAD, 2005. 